\title{
MAIS DO QUE NEGÓCIOS ABERTOS, MENTES ABERTAS'
}

DOI: 1014211/regepe.v5i2.346

Artigo recebido em: 24/01/2016

Artigo aprovado em: 03/03/2016

Glessia Silva -Universidade Federal de Alagoas - UFAL ${ }^{1}$ Antônio Luiz Rocha Dacorso - Universidade Federal de Sergipe - UFS ${ }^{2}$ Ludmilla Meyer Montenegro - Universidade Federal de Sergipe - UFS ${ }^{3}$

Resumo: Este artigo explora como as características interpessoais e gerenciais de gestores podem influenciar no uso do modelo de inovação aberta nas organizações de pequeno porte. Optou-se por agregar aos entendimentos acerca da inovação aberta as concepções básicas do organizing de Karl Weick (1973) para a compreensão da lógica cognitiva dos gestores e dos aspectos culturais das organizações. Os indícios teóricos apontaram que no contexto dos pequenos empreendimentos o modelo é fortemente influenciado pelas características interpessoais do gestor, grau de institucionalização da empresa, bem como por sua cultura e identidade. O modelo de inovação aberta precisa não apenas ser "lido" (interpretado) pelos gestores que irão incorporá-lo e utilizá-lo, mas também precisa fazer sentido para eles. Nesse sentido, para a efetiva adoção do modelo de inovação aberta é necessário criar uma atmosfera propícia à captação das novas fontes de valor, mudando o foco da empresa para a forma aberta de encarar a competição empresarial, tendo no gestor o principal responsável por essa mudança. Como contribuição desta pesquisa, está a análise baseada no indivíduo-gestor como forma de compreender a efetividade do modelo de inovação aberta nos empreendimentos de pequeno porte, em que a figura do dono e do gestor muitas vezes se confunde.

Palavras-chave: Modelo de Inovação Aberta; Organizing; Cultura Organizacional; Gestor; Pequenos Empreendimentos.

\section{MORE THAN OPENED BUSINESS, OPENED MINDS}

Abstract: This article explores how interpersonal and managerial characteristics influence the manager's use of the open innovation model in small organizations. For

\footnotetext{
1 Endereço: Rodovia AL 145, Km 3, no 3849, Cidade Universitária, Delmiro Gouveia - AL, CEP: 57480-000. E-mail: glessiasilva@hotmail.com

2 E-mail: antoniodacorso@gmail.com

3 E-mail: ludmilla2907@gmail.com
}

SILVA, G.; DACORSO, A. L. R.; MONTENEGRO, L. M. Mais do que negócios abertos, mentes abertas. Revista de Empreendedorismo e Gestão de Pequenas Empresas, v.5, n.2, 2016 
that, it has decided to add to understandings of open innovation, the basic concepts of organizing of Karl Weick (1973) for understanding the cognitive logic of managers and cultural aspects of organizations. The theoretical evidence showed that in the context of small enterprises the model is strongly influenced by interpersonal characteristics of the manager, degree of institutionalization of the company, as well as their culture and identity. The open innovation model must not only be believed "read" (interpreted) by managers who will incorporate and use it, but also to make sense to them. So for their effective adoption is necessary to create an atmosphere conducive to attracting new sources of value, changing the focus to the open face of corporate competition form and taking the officer primarily responsible for this change. As a contribution of this research, is the analysis based on individualmanager as a way to understand the effectiveness of the open innovation model in small enterprises, where the owner of the figure and the manager is often confused.

Keywords: Model of Open Innovation; Organizing; Organizational Culture; Manager; Small Businesses.

\section{Introdução}

Desenvolver inovações apenas por meio de competências internas tem se tornado um desafio para as empresas e seus gestores, pois é preciso tomar decisões rápidas num ambiente altamente competitivo (ROJAS; MONROY; PELUSO, 2011; BRUNSWICKER; EHRENMANN, 2013; SILVA; DACORSO, 2014a).

Esse dinamismo tem feito com que as organizações incorporem fontes externas de conhecimento, como clientes, fornecedores, governo, concorrentes, etc., em seus processos de inovação (CHESBROUGH, 2012a; CHESBROUGH, 2012b; PARIDA; WESTERBERG; FRISHAMMAR, 2012; SILVA; DACORSO, 2013a; SILVA; DACORSO, 2013b; SILVA; DACORSO, 2014a; SILVA; DACORSO, 2014b; IBARRA; RUEDA; ARENAS, 2015; LOVE; ROPER, 2015).

Isso tem tornado a relação colaborativa, o atual padrão competitivo das empresas (LAVIE; DRORI, 2012; VENTURINI; VERBANO; BRON, 2013). Esse formato de inovação é conhecido como modelo de inovação aberta (LINDEGAARD, 2011; CHESBROUGH, 2012a; CHESBROUGH, 2012b).

Esse cenário traz implicações para os gestores, já que precisam demonstrar confiança aos integrantes, montar uma rede colaborativa de inovação entre os participantes e organizar processos específicos de aprendizagem diante de

SILVA, G.; DACORSO, A. L. R.; MONTENEGRO, L. M. Mais do que negócios abertos, mentes abertas. Revista de Empreendedorismo e Gestão de Pequenas Empresas, v.5, n.2, 2016. 
conhecimentos muitas vezes em formação (AGOGUÉ et al., 2013; HAAPALAINEN; KANTOLA, 2015). Isso porque a cultura, normas, valores e relações interpessoais dos indivíduos são dimensões "informais" do modelo, de modo que na lógica da inovação aberta muitas vezes os valores estratégicos e culturais exercem maior importância que as normas formais e escritas, e sem elevado nível de confiança e interação seria difícil sua utilização (CHESBROUGH, 2013).

O modelo de inovação aberto exige, portanto, uma visão mais "aberta" por parte do gestor, tendo em vista ser ele o responsável por administrar as mudanças e fazer com que as práticas de fato reforcem os objetivos organizacionais (PINTO; COUTO-DE-SOUZA, 2009).

No caso das micro e pequenas empresas (MPEs), o papel do gestor se torna ainda mais determinante para a efetiva utilização do modelo (ROJAS; MONROY; PELUSO, 2011; BRUNSWICKER; EHRENMANN, 2013; DÍAZ-DÍAZ; SAÁ-PÉREZ, 2014), já que nesses empreendimentos o gestor e o dono do negócio muitas vezes figuram na mesma pessoa, de modo que sua visão de negócio se torna a visão e a cultura de negócio da empresa.

Além disso, por serem menos formais que as grandes empresas, a gestão da inovação nas MPEs muitas vezes é mais tácita (HOGENHUIS; VAN DEN HENDE; HULTINK, 2016), o que confere às capacidades de gestão, o sucesso pela efetividade do modelo de inovação aberta nessas organizações (BRUNSWICKER; EHRENMANN, 2013).

A noção de cultura organizacional torna-se, portanto, importante para compreender alguns aspectos relativos aos atores das organizações, uma vez que falar de cultura remete a crenças, valores, comportamentos e significados compartilhados (SCHEIN, 1997; LACOMBE; HEILBORN, 2009).

É preciso entender a cultura organizacional como algo criado e constantemente recriado nas organizações, e considerando que esse movimento é feito de forma intersubjetiva, isto é, considerando aspectos subjetivos (identidade, cognição, formas de compreender o mundo), mas também a relação com o outro, compreendendo que a realidade é construída com base em pensamentos e ações compartilhados (SCHEIN, 1984; SHEIN, 1997; BERGER; LUCKMANN, 2007). Pode-

SILVA, G.; DACORSO, A. L. R.; MONTENEGRO, L. M. Mais do que negócios abertos, mentes abertas. Revista de Empreendedorismo e Gestão de Pequenas Empresas, v.5, n.2, 2016 
se dizer que essa cultura é o que forma a ação coletiva da organização, é o que molda sua missão, visão e valores.

Assim, em uma pequena empresa, o gestor carrega consigo um conjunto de significados, de direcionamentos, de características e de aspectos que serão refletidos nas atividades, práticas, decisões e ações dos atores da organização. Esse conjunto de questões reflete não só internamente, mas também nos relacionamentos externos, já que muitas das relações, transações e atuações das organizações são praticadas além dos muros da própria empresa.

Acredita-se, portanto, que as práticas de gestão e a visão de negócio da organização podem determinar o direcionamento que a organização irá seguir no mercado, bem como a forma como irá lidar com aspectos internos e externos ao negócio.

Diante do exposto, este ensaio teórico busca explorar como as características interpessoais e gerenciais do gestor podem influenciar no uso do modelo de inovação aberta. Para tanto, optou-se por agregar aos entendimentos acerca da inovação aberta as concepções básicas do organizing de Karl Weick (1973), visto que se espera, por meio dessa abordagem, compreender a lógica cognitiva dos gestores e os aspectos culturais das organizações.

Para isso, Weick (1973), psicólogo social americano, propõe o modelo de organizing. $\mathrm{O}$ interesse em compreender a lógica cognitiva dos gestores de pequenos empreendimentos existe porque acredita-se que as atividades e práticas dos gestores permeiam o cotidiano da organização e estão atreladas à tomada de decisão e à incorporação ou não de um novo modelo de inovação aberta, além de moldarem a cultura organizacional.

Aliado a isso, embora o modelo de inovação aberta tenha sido largamente explorado na literatura, o entendimento sobre as peculiaridades de sua aplicação no contexto de pequenos empreendimentos ainda é incipiente (PARIDA; WESTERBERG; FRISHAMMAR, 2012; SANTORO et al., 2016), bem como os estudos que relacionam o papel do gestor e o uso do modelo de inovação aberta na pequena empresa (ROJAS; MONROY; PELUSO, 2011; BRUNSWICKER; EHRENMANN, 2013; DÍAZ-DÍAZ; SAÁ-PÉREZ, 2014). Em reforço a este último, a chamada de artigos do European Journal of Innovation Management, a ser

SILVA, G.; DACORSO, A. L. R.; MONTENEGRO, L. M. Mais do que negócios abertos, mentes abertas. Revista de Empreendedorismo e Gestão de Pequenas Empresas, v.5, n.2, 2016 
publicada em janeiro de 2017, retrata a necessidade de estudos que discutam as implicações das decisões gerenciais no uso do modelo de inovação aberta.

Espera-se, portanto, que o artigo contribua para uma compreensão melhor sobre como as características interpessoais e gerenciais do gestor podem influenciar no uso do modelo de inovação aberta nas organizações de pequeno porte. Cabe ressaltar que o objetivo do ensaio não é partir de uma lógica determinística, mas sim prover insights que permitam enxergar a temática sob uma perspectiva diferente (MENEGHETTI, 2011).

\section{Inovação Aberta: Uma Análise Voltada às Práticas de Gestão}

O modelo de inovação aberta consiste na busca intencional de insumos externos que permitam desenvolver novos produtos, serviços ou processos, sendo uma alternativa de inovação (CHESBROUGH, 2012a; GEUMA et al., 2013; SISODIYA; JOHNSON; GRÉGOIRE, 2013; OLIVEIRA; ALVES, 2014; SANTORO et al., 2016).

Dada sua ênfase nas fontes externas de conhecimento e por ter como base teorias de recursos e capacidades, o modelo permite às empresas um ambiente flexível e rico em conhecimento e maior capacidade de resposta e de adaptação ao mercado (FIGUEIREDO; GRIECO, 2013; GEUMA et al., 2013).

Entretanto, para trazer bons resultados, o modelo de inovação aberta deve ser tratado de forma estratégica, de forma que o foco deve residir nos parceiros externos e em como incorporar melhor tais parceiros dentro do planejamento da empresa (GEUMA et al., 2013).

Além disso, deve-se considerar que o modelo funciona de formas diferentes a depender da empresa e de sua utilização, de modo que as práticas de inovação aberta devem ser flexíveis a ponto de acomodar necessidades gerenciais diferenciadas e condições ambientais diversificadas (GEUMA et al., 2013; SANTORO et al., 2016).

Outro aspecto relevante é a gestão do processo de inovação aberta, já que o apoio da alta gerência é importante e os processos internos devem ser montados

SILVA, G.; DACORSO, A. L. R.; MONTENEGRO, L. M. Mais do que negócios abertos, mentes abertas. Revista de Empreendedorismo e Gestão de Pequenas Empresas, v.5, n.2, 2016 
visando aliar as fontes internas com as externas para viabilizar um processo de inovação (ROJAS; MONROY; PELUSO, 2011). Portanto, o principal fator a ser gerido é a capacidade relacional da organização (SISODIYA; JOHNSON; GRÉGOIRE, 2013).

Em uma pesquisa acerca dos elementos essenciais à inovação aberta em pequenos empreendimentos, Rojas, Monroy e Peluso (2011) obtiveram que os recursos humanos são fatores-chave para o funcionamento e correto gerenciamento e desempenho do modelo de inovação aberta. Para isso, deve haver motivação e trabalho em equipe. Esses aspectos são fruto da liderança e quando esquecidos podem trazer um baixo desempenho no uso do modelo de inovação aberta (ROJAS; MONROY; PELUSO, 2011).

De igual forma, Salter, Criscuolo e Wal (2014), ao tentarem compreender os desafios enfrentados pelos profissionais no uso do modelo de inovação aberta e as práticas que favorecem sua exploração, colocam os indivíduos como o principal componente do modelo, já que são os responsáveis por capturar os componentes externos de inovação. Os autores destacam a necessidade de analisar o modelo na perspectiva do indivíduo. O modelo exige uma mentalidade diferenciada e um ambiente interno favorável. Sem isso, todas as ações de inovação aberta serão ineficazes (ROJAS; MONROY; PELUSO, 2011; SISODIYA; JOHNSON; GRÉGOIRE, 2013; SALTER; CRISCUOLO; WAL, 2014).

Para os pequenos empreendimentos, o modelo se torna ainda mais importante (SANTORO et al., 2016), pois essas empresas demonstram necessitar das fontes de conhecimento externo em suas práticas (PARIDA; WESTERBERG; FRISHAMMAR, 2012; SILVA; DACORSO, 2013a; SILVA; DACORSO, 2013b; SILVA; DACORSO, 2014a; SILVA; DACORSO, 2014b; SANTORO et al., 2016). O modelo também podem servir como fonte de conhecimento para as grandes empresas no desenvolvimento de aspectos específicos do negócio (LIU; LAPERCHE, 2015; HOGENHUIS; VAN DEN HENDE; HULTINK, 2016; VENTURINI; VERBANO; BRON, 2013).

A gestão do modelo de inovação aberta nos pequenos empreendimentos torna-se ainda mais determinante para sua efetiva utilização ou até mesmo para classificar uma empresa como aderente ao modelo de inovação aberta. Isso porque

SILVA, G.; DACORSO, A. L. R.; MONTENEGRO, L. M. Mais do que negócios abertos, mentes abertas. Revista de Empreendedorismo e Gestão de Pequenas Empresas, v.5, n.2, 2016. 
as decisões a serem tomadas são de responsabilidade do dono/gestor, que deve formular, implementar e avaliar as estratégias de inovação aberta utilizadas (ROJAS; MONROY; PELUSO, 2011).

A importância da gestão e da cultura no funcionamento do modelo de inovação aberta pode ser visto nos estudos de Haapalainen e Kantola (2015), que trazem como indicativo o estudo da cultura para a boa gestão do modelo de inovação aberta. Nessa linha, Brunswicker e Ehrenmann (2013) afirmam que mais do que sistemas e processos articulados de inovação aberta, as empresas devem possuir a capacidade de atuação conjunta, gerenciamento colaborativo e integrado, de modo que três aspectos sustentem o modelo: confiança, vontade e capacidades individuais.

Rojas, Monroy e Peluso (2011), ao estudarem o modelo de inovação aberta no contexto dos pequenos empreendimentos, concluíram como fundamentais à incorporação do modelo de inovação aberta: o compromisso gerencial, a formação de uma cultura de inovação que propicie o trabalho em equipe, a motivação e capacitação de recursos humanos e o aproveitamento de fontes internas e externas no processo de inovação.

Os gestores devem avaliar as fontes de conhecimento externo adquiridas e implementar suas estratégias em conformidade com essas fontes, no intuito de possibilitar que o modelo atenda às necessidades da empresa, além de conhecer bem suas estruturas internas, a fim de fazer com que as ações tomadas agreguem valor e combinem-se com as fontes internas (DÍAZ-DÍAZ; SAÁ-PÉREZ, 2014). Isso pode ser conquistado por meio de uma cultura de inovação sólida e repercutida pelo gestor (BRUNSWICKER; EHRENMANN, 2013).

Entre os desafios impostos pelo uso do modelo de inovação aberta está a mudança organizacional interna para lidar com as fontes de conhecimento externo, como parceiros no processo de inovação. Assim, fazer com que as mudanças organizacionais ocorram é o fator mais difícil e mais crítico para a aplicação do modelo, uma vez que a formação de uma cultura que suporte a inovação aberta se mostra determinante no uso do modelo.

SILVA, G.; DACORSO, A. L. R.; MONTENEGRO, L. M. Mais do que negócios abertos, mentes abertas. Revista de Empreendedorismo e Gestão de Pequenas Empresas, v.5, n.2, 2016. 


\section{Compreendendo a Cultura Organizacional e o Estilo de Gestão por meio do Modelo de Organizing de Karl Weick}

Antes de apresentar o modelo de organizing de Weick (1973), é importante compreender suas origens. As concepções teóricas de Weick têm como base três teorias: a Teoria da Evolução Sociocultural, a Teoria da Informação e a Teoria dos Sistemas (KREPS, 1990). Os pontos principais das teorias usadas por Weick para a composição dos pressupostos teóricos de seu modelo estão dispostos no Quadro 1.

QUADRO 1 - PRINCIPAIS ASPECTOS DAS TEORIAS-BASE DO MODELO DE ORGANIZING DE WEICK (1973).

\begin{tabular}{|c|c|}
\hline Teoria & Principais aspectos utilizados por Weick \\
\hline $\begin{array}{l}\text { Teoria da } \\
\text { Evolução } \\
\text { Sociocultural }\end{array}$ & $\begin{array}{l}\text { O processo de evolução sociocultural que acontece nas organizações é um } \\
\text { processo que envolve inovação, escolha e persistência (WEICK, 1990). O } \\
\text { modelo de Weick prevê uma lógica evolutiva em três fases, que possuem } \\
\text { semelhança com as fases propostas por essa teoria (variação, seleção e } \\
\text { retenção). }\end{array}$ \\
\hline $\begin{array}{l}\text { Teoria da } \\
\text { Informação }\end{array}$ & $\begin{array}{l}\text { O processo organizacional é uma tentativa dos membros da organização de } \\
\text { reduzir a incerteza ao gerar informação através do uso de regras e ciclos. O } \\
\text { princípio básico da Teoria da Informação é que um dado configura-se como } \\
\text { uma informação quando consegue reduzir incertezas. A noção de incerteza } \\
\text { permeia todo o modelo de Weick, já que, para o autor, os indivíduos nas } \\
\text { organizações se organizam para lidar com as incertezas provenientes do } \\
\text { ambiente. }\end{array}$ \\
\hline $\begin{array}{l}\text { Teoria dos } \\
\text { Sistemas }\end{array}$ & $\begin{array}{l}\text { "Cada nível da organização é composto por componentes interconectados e } \\
\text { mutuamente influenciados, e cada qual desempenha um processo funcional no } \\
\text { nível do sistema do qual faz parte. A combinação de todos esses processos } \\
\text { funcionais permite a sobrevivência do sistema e sua adaptação ao ambiente. O } \\
\text { desempenho de um componente irá afetar todos os outros componentes" } \\
\text { (MONTENEGRO; CASALI, 2008, p. 03). Para Weick (1979), as áreas funcionais } \\
\text { das organizações e seus membros estão interligados e fazem parte de um } \\
\text { processo dinâmico. Além da importância da inter-relação, Weick (1979) também } \\
\text { considera importante a noção de feedback (retorno positivo e negativo) que faz } \\
\text { parte da Teoria dos Sistemas. }\end{array}$ \\
\hline
\end{tabular}

FONTE: Adaptado de Weick (1979), Kreps (1990) e Montenegro e Casali (2008).

Após essa breve contextualização, apresenta-se o modelo na Figura 1.

SILVA, G.; DACORSO, A. L. R.; MONTENEGRO, L. M. Mais do que negócios abertos, mentes abertas. Revista de Empreendedorismo e Gestão de Pequenas Empresas, v.5, n.2, 2016. 
FIGURA 1 - MODELO DE ORGANIZING DE WEICK

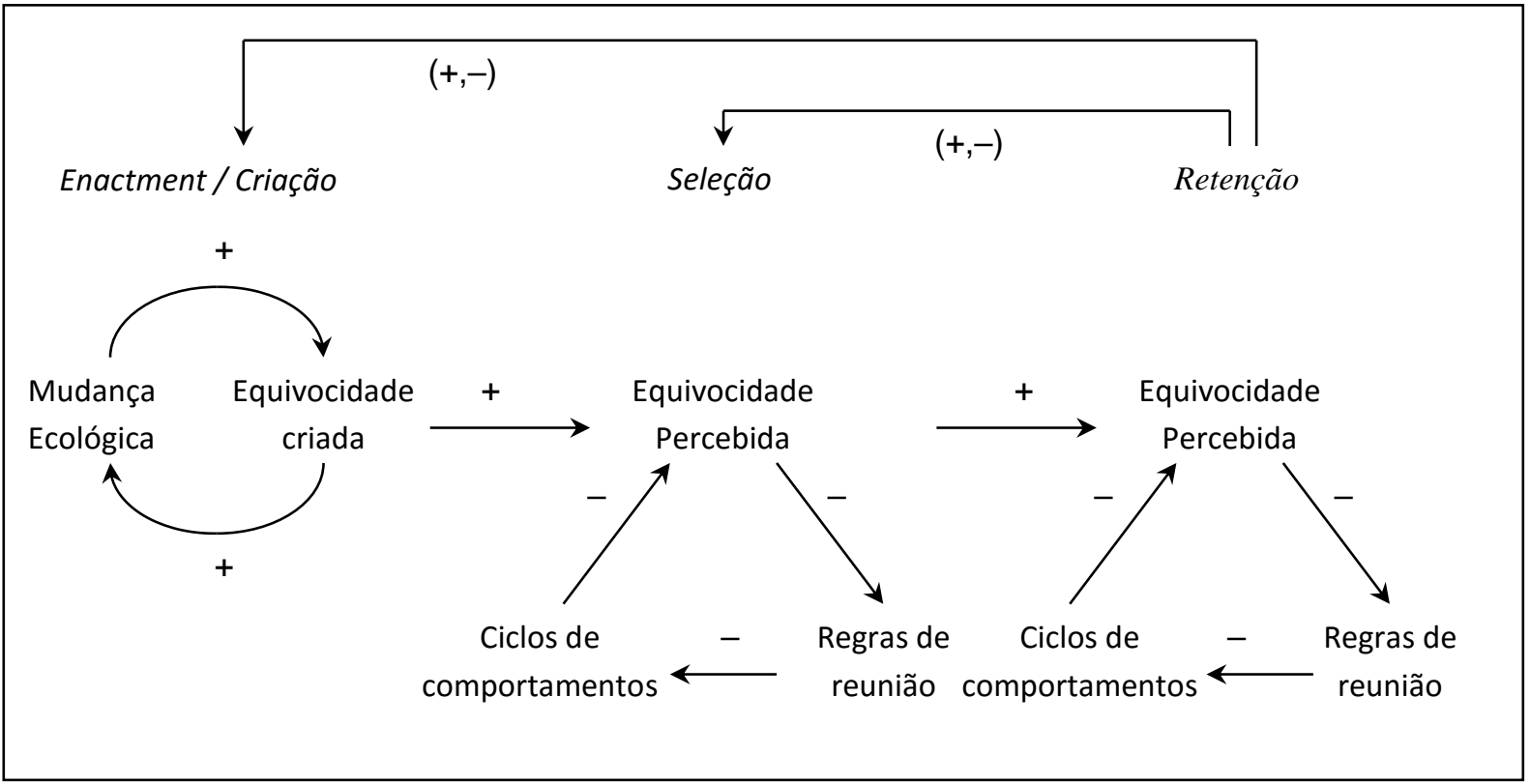

FONTE: Weick (1979).

Observa-se a lógica relativa a um processo de evolução, uma vez que o autor constrói seu modelo com base em três pilares principais: (1) criação; (2) seleção; e (3) retenção. Em cada uma dessas fases, são previstos os seguintes subprocessos: regras de reunião, ciclos de comportamento interligados e afastamento da ambiguidade (BANTZ; SMITH, 1977).

Em uma organização, onde constantemente há relações e interações entre seus membros, há dois pontos de escolha: um referente à maneira de agir (fase de criação) e outro referente ao que escolher (fase de seleção) (MONTENEGRO; CASALI, 2008). Pode-se dizer que na fase de criação, os ciclos adequados para esse processo referem-se a fazer, agir e realizar. É a fase das tentativas e experimentações (MONTENEGRO; CASALI, 2008).

Já na fase de seleção, os ciclos adequados se referem a escolhas das ações anteriores que devem ser repetidas, reconhecidas e consideradas como experiência benéfica, de forma que as primeiras ações servirão de referência para as seguintes (MONTENEGRO; CASALI, 2008).

SILVA, G.; DACORSO, A. L. R.; MONTENEGRO, L. M. Mais do que negócios abertos, mentes abertas. Revista de Empreendedorismo e Gestão de Pequenas Empresas, v.5, n.2, 2016 
Com relação aos ciclos, eles se referem a algum aspecto de comportamento de escolha. É importante frisar que as escolhas feitas na fase de seleção atuam no ambiente que é sugerido pela fase de criação. Portanto, deve-se ter bastante cautela com relação às escolhas feitas, visto que elas deverão "atuar" no ambiente na fase de criação, ou seja, o processo prevê uma lógica interligada e o que é feito (e escolhido) em uma fase terá relação direta com as outras fases.

Destaca-se também que as informações podem vir do ambiente interno ou externo, ou seja, existem informações de dentro do sistema (a linha da retenção à criação) e de fora do sistema (a linha da mudança ecológica à criação) (WEICK, 1979). Essa característica corrobora a noção de inovação, que pode ter origem no interior das organizações, mas também pode ser proveniente de ideias e oportunidades encontradas no ambiente externo.

As linhas colocadas entre mudança ecológica e criação, criação e seleção, e seleção e retenção, representam a transmissão de informação de uma fase para a outra. Destaca-se que a informação que é transferida é carregada de incerteza (no modelo, usou-se o termo equivocidade) e que, ao passar por cada uma das fases do processo de organizing, parte dessa incerteza deverá ser afastada. Assim, enfatizase que as linhas que partem de uma fase a outra não se referem apenas à informação, mas a uma informação carregada de diversos graus de incerteza (WEICK, 1979).

A incerteza é registrada pelo aumento ou redução no número de regras que são "ativadas" para compor um determinado processo. Caso a organização disponha de muitas regras para lidar com determinado aspecto do ambiente, isso significa que essa informação carrega pouca incerteza (WEICK, 1979). Por outro lado, se frente a uma mudança ambiental, a organização não sabe como agir é porque possui poucas regras para processar aquela informação nova (WEICK, 1979). Destaca-se que o número de regras influencia a maneira pela qual o processo é reunido, portanto, o número de regras irá ditar a lógica seguinte, a dos subprocessos (WEICK, 1979).

A quantidade de incerteza numa informação percebida determina o grau de incerteza de um processo. Há uma relação direta entre informações e processos, assim, quanto mais carregada de incerteza for a informação, mais ambíguo será o

SILVA, G.; DACORSO, A. L. R.; MONTENEGRO, L. M. Mais do que negócios abertos, mentes abertas. Revista de Empreendedorismo e Gestão de Pequenas Empresas, v.5, n.2, 2016. 
processo e quanto menos carregada de incerteza for a informação, menos ambíguo será o processo (MONTENEGRO; CASALI, 2008). Como a evolução dos processos e o desenvolvimento dos subprocessos são comportamentos interligados, a redução da incerteza é uma atividade coletiva realizada por conjuntos de membros da organização que interligam diferentes conjuntos de comportamentos (WEICK, 1979).

Nesse momento, convém destacar que o estilo de gestão irá aparecer à medida que os gestores se comportarem e irá direcionar os membros da organização a fazerem suas escolhas e a criarem suas regras e ciclos. Numa pequena empresa, onde há uma pequena quantidade de pessoas envolvidas com o processo, provavelmente haverá pouca ou nenhuma mescla de estilos de gestão. Diante disso, deverá aparecer claramente o estilo de gestão do único gestor da empresa (do proprietário).

Contudo, é importante frisar que o trabalho coletivo, principalmente em empresas de grande porte, tem um peso significativo nesse processo, uma vez que cada ciclo de comportamento interligado é capaz de afastar uma carga de incerteza, mas somente quando vários ciclos diferentes são aplicados à informação é que um grau suficiente de certeza é alcançado e, a partir disso, torna-se possível uma ação não ambígua. No caso da pequena empresa, provavelmente, deverá haver um esforço e empenho maior no que se refere à compreensão das formas de agir, decidir, escolher e se comportar dos gestores envolvidos.

Os ciclos comportamentais interligados aparecem nas três fases (criação, seleção e retenção). O processo de criação gera a informação, com isso, o sistema se adapta e afasta uma pequena parte da incerteza. Contudo, a incerteza reduzida é muito menor do que aquela afastada pelos processos seguintes (seleção e retenção). Assim, entende-se que a maior parcela de incerteza é afastada pelo último processo (retenção) (MONTENEGRO; CASALI, 2008).

A partir das regras de reunião, o processo de seleção separa a diversidade presente na informação incerta, absorve as partes que satisfazem estas regras e, de certa forma, organiza a informação ambígua, ou seja, atribui um significado a esta informação. Embora o processo final (retenção) seja basicamente um processo de armazenamento, destaca-se que nele também se reduz parte da incerteza, visto que há a integração de novas informações ou interpretações àquelas anteriormente

SILVA, G.; DACORSO, A. L. R.; MONTENEGRO, L. M. Mais do que negócios abertos, mentes abertas. Revista de Empreendedorismo e Gestão de Pequenas Empresas, v.5, n.2, 2016. 
acumuladas. Os três processos estão inter-relacionados e constituem um sistema. Observa-se uma relação de controle entre os processos (WEICK, 1979).

Por meio desse modelo, Weick (1979) tem a intenção de ressaltar algumas propriedades da organização que comumente passam despercebidas. Dessa forma, seu modelo ajuda a compreender o motivo pelo qual alguns aspectos do ambiente são evidenciados enquanto outros são ignorados (WEICK, 1979), entendendo que, independente do que for acessado no ambiente (informação, inovação, conhecimento, etc.) e, consequentemente, processado, deverá fazer sentido para aqueles atores que entram em contato com essa nova informação. Isso ocorrerá com base nas fases mencionadas, na quantidade de incerteza, bem como nas regras e ciclos de comportamento desenvolvidos e retidos nas organizações.

\section{Entre a Visão e a Ação: Uma Reflexão Acerca do Papel do Gestor na} Efetividade do Modelo de Inovação Aberta nas Organizações de Pequeno Porte

Para Weick (1979), as organizações são entidades complexas e possuem característica dinâmica. Essa noção de movimento, vista por Weick na lógica organizacional, reflete-se também nos termos utilizados por ele. $O$ autor prefere utilizar verbos (sensemaking, organizing, etc.) a substantivos, já que os verbos levam consigo a ideia de continuidade, de movimento e, consequentemente, de mudança. Segundo Weick (1979), as organizações não são entidades monolíticas e estáveis. Portanto, pode-se dizer que a noção de processo faz mais sentido para Weick no que se refere ao entendimento da lógica organizacional.

Todavia, compreender as organizações como entidades processuais que mudam constantemente não significa dizer que essa mudança é aleatória, acontece de qualquer forma. Portanto, a organização é um contínuo que está à mercê da relatividade. Para Weick (2009), a mudança existe, não se pode negá-la, mas é preciso que haja um mínimo de ordem, de padrões estabelecidos pelos integrantes dessas organizações (que podem ser resignificados e atualizados) para que eles possam agir com base em parâmetros e em situações que façam sentido para eles. Weick (2009) destaca que é interessante observar que as perspectivas que tratam de mudança organizacional apenas mencionam e instigam a mudar, não o contrário.

SILVA, G.; DACORSO, A. L. R.; MONTENEGRO, L. M. Mais do que negócios abertos, mentes abertas. Revista de Empreendedorismo e Gestão de Pequenas Empresas, v.5, n.2, 2016. 
Nesse momento, convém destacar que essa lógica do organizing de Weick (1979) parece corroborar com a lógica de inovação aberta, uma vez que essa referese a inovar com base nas oportunidades advindas de fora do ambiente organizacional, contudo, isso não significa apenas trazer um modelo e inseri-lo na realidade organizacional.

Conforme consta na literatura mais recente sobre inovação aberta (ROJAS; MONROY; PELUSO, 2011; AGOGUÉ et al., 2013; FIGUEIREDO; GRIECO, 2013; BRUNSWICKER; EHRENMANN, 2013; CHESBROUGH, 2013; DÍAZ-DÍAZ; SAÁPÉREZ, 2014; SALTER; CRISCUOLO; WAL, 2014; SANTORO et al., 2016), a escolha do modelo de inovação é fortemente influenciada por fatores que dizem respeito às características interpessoais do gestor, ao grau de institucionalização da empresa, bem como de sua cultura e identidade.

Assim, percebe-se que as perspectivas teóricas adotadas nesse trabalho parecem estar alinhadas, uma vez que no modelo de organizing de Weick, as informações provenientes do ambiente externo são processadas e absorvidas pela organização. Mas esse processo precisa fazer sentido para os membros da organização envolvidos com esse processo. Para isso, são criadas e armazenadas regras que serão utilizadas novamente para uma nova informação (ou modelo, ou conhecimento) que a organização decidirá inserir na sua realidade organizacional.

Ressalta-se que são os gestores (com seus esquemas interpretativos, cognições, aspectos culturais e identidades) que irão filtrar essa informação que vem do ambiente externo (ou interno), decidir quais regras adotar e, consequentemente, escolher a forma como essa informação será retida e utilizada pela organização. A isso, Weick (1979) chama de processo evolutivo, em que diferentes informações são constantemente processadas. Para o autor, esse movimento é o que compõe as próprias organizações (MONTENEGRO; CASALI, 2008).

Ao se debruçar nas fases do organizing - criação, seleção e retenção -, temse que na fase de criação, caracterizada pelo fazer, agir, realizar, o gestor deve identificar fontes de conhecimento externas significativas ao negócio. Isso se dá por meio da percepção de quais fontes se adequam às necessidades da organização e melhor se combinam com as competências internas da empresa. Sobre isso, Geuma et al. (2013) evidenciam que as fontes de conhecimento externo devem ser

SILVA, G.; DACORSO, A. L. R.; MONTENEGRO, L. M. Mais do que negócios abertos, mentes abertas. Revista de Empreendedorismo e Gestão de Pequenas Empresas, v.5, n.2, 2016 
escolhidas visando relacioná-las melhor com os objetivos que se pretende atingir, formando combinações únicas de acordo com a empresa que as utilize.

Como a fase de criação antecede as demais fases, as decisões tomadas, como aponta Weick (1979), irão repercutir nas demais fases, criando uma trajetória de inovação dependente ou influenciada por estas decisões. Em virtude disso, quanto mais bem explorados os preceitos do modelo de inovação aberta mediante as ações do gestor, maiores as chances de utilização de seu potencial de inovação. O gestor deve, portanto, conhecer bem o seu papel como líder e fazer com que as ações de inovação sejam tomadas tendo como base um conhecimento prévio e sólido acerca do modelo e das fontes de conhecimento externo, examinando as potencialidades, limitações e pretensões dos entes externos envolvidos.

$\mathrm{Na}$ fase de seleção, as ações de inovação aberta tidas como significativas são escolhidas para comporem o modelo de inovação aberta da organização, de modo que uma empresa pode preferir algumas fontes em detrimento de outras, ou verificar quais competências externas se enquadram com as necessidades de inovação da empresa. No modelo de Weick, as informações utilizadas em todas as fases podem ter origem tanto de dentro da organização quanto de fora, de modo que ao relacioná-lo à lógica do modelo de inovação aberta, tais informações podem ser representadas pelas competências internas, advindas das capacidades internas da organização em inovar, e das competências externas, advindas das fontes de conhecimento externo.

O gestor, seguindo a perspectiva defendida pelo organizing, pode ser associado a um mediador na combinação das competências internas e externas, no intuito de fazer fluir o modelo pela organização, mediante as práticas incentivadas e disseminadas por ele junto aos demais integrantes da empresa. Os apontamentos feitos por Agogué et al. (2013) corroboram esse argumento. Eles enfatizam que um aspecto importante aos gestores é a disseminação de um objetivo em comum, a fim de garantir a coesão dos demais participantes rumo aos objetivos de inovação previamente estabelecidos.

Em relação às linhas colocadas entre mudança ecológica e criação, criação e seleção, e seleção e retenção, presentes no organizing, representam a transmissão de informação de uma fase para a outra. Caso a organização disponha

SILVA, G.; DACORSO, A. L. R.; MONTENEGRO, L. M. Mais do que negócios abertos, mentes abertas. Revista de Empreendedorismo e Gestão de Pequenas Empresas, v.5, n.2, 2016. 
de muitas regras para lidar com determinado aspecto do ambiente, isso significa que esta informação carrega pouca incerteza. Por outro lado, se frente a uma mudança ambiental, a organização não sabe como agir é porque possui poucas regras para processar aquela nova informação (WEICK, 1979).

Desse modo, na perspectiva do modelo de inovação aberta o grau de incerteza pode ser refletido nas ações do gestor, de modo que quanto mais convicto de seu papel na efetividade do modelo de inovação aberta e na formação de uma cultura de inovação aberta sólida, maior é o grau cognitivo de aceitação e compreensão do modelo, menor o nível de incerteza diante de sua utilização e mais efetivo o seu papel nos resultados de inovação gerados por ele, uma vez que os preceitos do modelo e sua potencial exploração serão disseminados por ele.

Tal afirmativa pode ser observada no estudo de Silva e Dacorso (2014a) que, ao investigarem como o uso do modelo de inovação aberta pode reduzir os riscos e incertezas presentes na decisão de inovar, evidenciam que a adoção do modelo de inovação aberta nas empresas de pequeno porte parte do gestor, que é responsável por selecionar as fontes de conhecimento externas mais adequadas ao seu negócio e enxergar no modelo de inovação aberta uma nova forma de competir.

Por outro lado, quando o próprio gestor não se identifica com os preceitos do modelo e não reconhece suas eventuais vantagens, mesmo diante da necessidade de utilizá-lo na organização, menor se torna o grau cognitivo de aceitação e compreensão do modelo, maior é o nível de incerteza e menos efetivos são os resultados gerados, uma vez que as ações a serem repercutidas estarão permeadas de dúvidas e descrédito, prejudicando a formação de uma cultura colaborativa de inovação aberta.

Quando o modelo de inovação aberta é utilizado dentro de um ambiente pouco favorável ao seu uso, os processos de inovação são comprometidos, uma vez que as fontes de conhecimento externo, base do modelo, são vistas com desconfiança e as relações acabam não gerando os resultados pretendidos. Assim, pode existir um descompasso entre o discurso e a ação, levando à adoção do modelo de inovação aberta sem sua efetiva utilização. Aliado a isso, tal situação pode comprometer os processos de inovação já existentes, prejudicando a capacidade interna de inovação das organizações.

SILVA, G.; DACORSO, A. L. R.; MONTENEGRO, L. M. Mais do que negócios abertos, mentes abertas. Revista de Empreendedorismo e Gestão de Pequenas Empresas, v.5, n.2, 2016. 
Esse argumento é explorado por Salter, Criscuolo e Wal (2014). Eles relatam que há grande preocupação com as organizações ao se pensar no modelo de inovação aberta enquanto que os indivíduos e responsáveis pela execução das práticas de inovação são pouco levados em consideração, bem como suas escolhas e comportamentos. Os autores argumentam que pode haver um conflito entre as práticas reais e as práticas preconizadas pela organização, de modo que para o modelo de fato fluir dentro da empresa, é necessário avaliar o papel dos indivíduos dentro da lógica do modelo de inovação aberta.

No momento em que os processos e subprocessos são desenvolvidos, os diversos atores que compõem esses processos e subprocessos emergem e apresentam múltiplos comportamentos, que podem ser direcionados pelo gestor, conforme seu estilo de gestão. É nesse ponto específico que o modelo de Weick presta a sua maior contribuição à lógica da inovação aberta, uma vez que a crença e o conhecimento do gestor acerca do modelo podem fazer com que as ações desenvolvidas pelos atores também sejam voltadas ao modelo. Por outro lado, sua falta pode refletir nas ações e orientar práticas contrárias, gerando uma cultura e um ambiente interno desfavorável ao uso efetivo do modelo de inovação aberta.

Tais concepções explicam porque muitas empresas, apesar de inseridas num ambiente repleto de fontes de conhecimento externo não as utilizam enquanto outras utilizam-nas com sucesso, e pode explicar o porquê de algumas empresas tentarem aplicar o modelo sem obterem sucesso. Segundo Chesbrogh (2012a), a inovação aberta ocorre necessariamente em uma lógica colaborativa e uma cultura que suporte a inovação aberta, de modo que sem isso não existe modelo de inovação aberta, mas sim ações isoladas que pouco refletem o modelo.

Diante disso, por meio das concepções do conceito de organizing proposto por Weick (1979), destaca-se que um modelo de inovação aberta adotado por uma organização chega a essa organização permeado de lógica e sentido, uma vez que as pessoas que criaram o modelo utilizaram (de forma consciente ou não) referências provenientes do meio cultural em que convivem, portanto, de suas crenças, valores e significados compartilhados. Elementos mais intrínsecos, como aspectos cognitivos, identidade e personalidade também podem estar presentes, em menor ou maior grau, nesse modelo.

SILVA, G.; DACORSO, A. L. R.; MONTENEGRO, L. M. Mais do que negócios abertos, mentes abertas. Revista de Empreendedorismo e Gestão de Pequenas Empresas, v.5, n.2, 2016 
Diante disso, acredita-se que o modelo de inovação aberta precisa não apenas ser "lido" (interpretado) pelos gestores que irão incorporá-lo e utilizá-lo na organização, mas também precisa fazer sentido para eles. O fazer sentido se dará na prática, na utilização efetiva do modelo. É neste momento que estabelecem padrões, regras e formas de lidar com as informações que entram na organização.

\section{Considerações Finais}

O presente artigo buscou explorar como as características interpessoais e gerenciais do gestor podem influenciar no uso do modelo de inovação aberta nas organizações de pequeno porte. O intuito foi explorar o processo de inovação aberta como fruto da mentalidade do gestor e refletir sobre como a organização cria bases legítimas de visão e cultura que as façam encarar tal processo como um dos aspectos de sua identidade.

A articulação empreendida nesse ensaio teórico permite uma reflexão acerca da importância dos estilos de gestão, visto que eles, de certa forma, direcionam os gestores a decidir o modelo de inovação aberta mais apropriado para sua organização. E como saber qual é o mais adequado? Qual deles será melhor executado na organização? As discussões geradas nesse artigo, por meio do modelo de organizing de Weick (1973), parecem ser um caminho interessante para repensar essas questões e a efetividade do modelo de inovação escolhido.

Cabe ressaltar que a menção de qual modelo deve ser adotado refere-se aos diferentes tipos de combinações permitidas por meio da preferência sobre determinadas fontes de conhecimento em detrimento de outras, de modo que o formato de inovação aberta a ser adotado dependerá das combinações internas e externas propiciadas pelo modelo.

Diante disso, o gestor deve ser capaz de identificar quais fontes de conhecimento externo são importantes ao negócio e melhor se aliam às competências internas já existentes e como perpetuar práticas coerentes com a lógica de inovação aberta e com os objetivos organizacionais. O intuito é motivar os

SILVA, G.; DACORSO, A. L. R.; MONTENEGRO, L. M. Mais do que negócios abertos, mentes abertas. Revista de Empreendedorismo e Gestão de Pequenas Empresas, v.5, n.2, 2016. 
diversos atores da organização e criar uma cultura e ambiente favoráveis ao uso efetivo do modelo de inovação aberta.

Em relação à construção deste trabalho, cabe destacar que um dos principais objetivos de um artigo ensaístico é promover reflexões que levem a múltiplos questionamentos e proporcionem diferentes ideias e concepções, mediante o pensamento crítico e livre, porém lógico e científico, de modo a apresentar ao leitor uma perspectiva teórica diferente e possibilitar a construção de suas próprias concepções e achados (MENEGHETTI, 2011).

Assim, como contribuição da pesquisa, há a análise baseada no indivíduogestor como forma de compreender a efetividade do modelo de inovação aberta, principalmente no contexto de pequenos empreendimentos, em que a figura do dono e do gestor muitas vezes se confunde.

O conceito de organizing proposto por Weick se aplica na compreensão do modelo de inovação aberta nessas organizações ao colocar que, quando os processos e subprocessos são desenvolvidos, os diversos atores que compõem esses processos e subprocessos emergem e apresentam múltiplos comportamentos, podendo serem direcionados pelo gestor, conforme o seu estilo de gestão. Isso fornece uma ligação direta entre as ações desenvolvidas pelo gestor e as ações repercutidas na organização.

Frente aos indícios teóricos apontados nesta pesquisa, sugere-se a realização de estudos empíricos que explorem como as práticas de inovação são efetivamente disseminadas na organização, no intuito de averiguar se existe conformidade entre o discurso e a prática de inovação, bem como pesquisas que se debrucem sobre o papel do gestor no modelo de inovação aberta.

\section{Referências:}

AGOGUÉ, M.; BERTHET, E.; FREDBERG, T.; MASSON, P.; SEGRESTIN, B.; STOETZEL, M.; WIENER, M.; YSTRÖM, A. A contingency approach to open innovation intermediaries: the management principles of the "intermediary of the unknown". In: 13th CONFERENCE OF THE EUROPEAN ACADEMY OF MANAGEMENT (EURAM), 2013, Istanbul/TR, Conference... Istanbul, 2013. p. 2629.

SILVA, G.; DACORSO, A. L. R.; MONTENEGRO, L. M. Mais do que negócios abertos, mentes abertas. Revista de Empreendedorismo e Gestão de Pequenas Empresas, v.5, n.2, 2016 
BANTZ, C. R.; SMITH, D. H. A Critique and Experimental Test of Weick's Model of Organizing. Communication Monographs, v. 44, n. 3, p. 171-184, 1977.

BERGER, L.; LUCKMANN, T. A construção social da realidade: tratado de sociologia do conhecimento. 27. ed. Petrópolis: Vozes, 2007.

BRUNSWICKER, S.; EHRENMANN, F. Managing open innovation in SMEs: a good practice example of a German software firm. International Journal of Industrial Engineering and Management (IJIEM), v. 4, n. 1, p. 33-41, 2013.

CHESBROUGH, H. Inovação aberta: como criar e lucrar com a tecnologia. Tradução de: FARIA, L. C. de Q. Porto Alegre: Bookman, 2012a.

CHESBROUGH, H. Modelos de negócios abertos: como prosperar no novo cenário da inovação. Tradução de: RUBENICH, R. Porto Alegre: Bookman, 2012b.

$\mathrm{CHESBROUGH}, \mathrm{H}$. Managing open innovation in large firms. Fraunhofer Society, 2013.

DÍAZ-DÍAZ, N. L.; SAÁ-PÉREZ, P. The interaction between external and internal knowledge sources: an open innovation view. Journal of Knowledge Management, v. 18, n. 2 , p. $430-446,2014$.

EUROPEAN JOURNAL OF INNOVATION MANAGEMENT. Start-ups and Open Innovation: Special issue call for papers from European Journal of Innovation Management. em: $<$ http://www.emeraldgrouppublishing.com/products/journals/call_for_papers.htm?id= $6121>$. Acesso em: 10 out. 2015.

FIGUEIREDO, J. C. B.; GRIECO, A. M. O papel da inovação aberta na internacionalização de empresas em rede: o caso Brasil Foods. Revista de Administração e Inovação, v. 10, n. 4, p. 63-84, 2013.

GEUMA, Y.; KIM, J.; SON, C.; PARK, Y. Development of dual technology roadmap (TRM) for open innovation: structure and typology. J. Eng. Technol. Manage, v. 30, n. 3, p. 309-325, 2013.

HAAPALAINEN, P.; KANTOLA, J. Taxonomy of Knowledge Management in Open Innovations. Procedia Manufacturing, v. 3, p. 688-695, 2015.

HOGENHUIS, B. N.; VAN DEN HENDE, E. A.; HULTINK, E. J. When Should Large Firms Collaborate with Young Ventures? Understanding young firms' strengths can help firms make the right decisions around asymmetric collaborations. ResearchTechnology Management, v. 59, n. 1, p. 39-47, 2016.

IBARRA, E. R. B.; RUEDA, J. A. C.; ARENAS, A. P. L. Mapping of the Challenges for the Open Innovation Model's Implementation in Service Sector. Journal of Advanced Management Science, v. 3, n. 4, 2015.

SILVA, G.; DACORSO, A. L. R.; MONTENEGRO, L. M. Mais do que negócios abertos, mentes abertas. Revista de Empreendedorismo e Gestão de Pequenas Empresas, v.5, n.2, 2016. 
KREPS, G. L. Weick's Model of Organizing. In:_. Organizational communication: theory and practice. New York: Longman, 1990. p. 103-121.

LACOMBE, F.; HEILBORN, G. Administração: princípios e tendências. 2. ed. São Paulo: Saraiva, 2009.

LAVIE, D.; DRORI, I. Collaborating for Knowledge Creation and Application: The Case of Nanotechnology Research Programs. Organization Science, v. 23, n. 3, p. 704-724, 2012.

LINDEGAARD, S. A revolução da inovação aberta: princípios básicos, obstáculos e habilidades de liderança. São Paulo: Évora, 2011.

LIU, Z.; LAPERCHE, B. The knowledge capital of SMEs: The French paradox. Journal of Innovation Economics \& Management, v. 17, n. 2, p. 27-48, 2015.

LOVE, J. H.; ROPER, S. SME innovation, exporting and growth: A review of existing evidence. International Small Business Journal, v. 33, n. 1, p. 28-48, 2015.

MENEGHETTI, F. K. O que é um Ensaio-Teórico? Revista de Administração Contemporânea, v. 15, n. 2, p. 320-332, 2011.

MONTENEGRO, L. M.; CASALI, A. M. O Modelo de Organizing de Karl Weick e sua Ênfase na Comunicação. In: $V$ ENEO - ENCONTRO DE ESTUDOS ORGANIZACIONAIS, 2008, Belo Horizonte. Anais... 2008.

OLIVEIRA, S. M.; ALVES, J. L. Influência das práticas de inovação aberta na prospecção de conhecimentos para a criação de valor em ambientes de alta complexidade sob condições de incerteza e imprevisibilidade. Revista de Administração e Inovação, v. 11, n. 1, p. 295, 2014.

PARIDA, V.; WESTERBERG, M.; FRISHAMMAR, J. Inbound open innovation activities in high-tech SMEs: the impact on innovation performance. Journal of Small Business Management, v. 50, n. 2, p. 283-309, 2012.

PINTO, M. C. S.; COUTO-DE-SOUZA, C. L. Mudança organizacional em uma empresa familiar brasileira. Revista de Administração Pública, v. 43, n. 3, p. 609634, 2009.

ROJAS, A. T.; MONROY, C. R.; PELUSO, N. B. La innovación abierta como elemento de análisis en las pequeñas y medianas industrias: caso sector metalmecánico. Revista de Administração e Inovação, v. 8, n. 2, p. 5-28, 2011.

SALTER, A.; CRISCUOLO, P.; WAL, A. L. J. Coping with Open Innovation: responding to the challenges of external engagement in R\&D. California Management Review, v. 56, n. 2, p. 77-94, 2014.

SILVA, G.; DACORSO, A. L. R.; MONTENEGRO, L. M. Mais do que negócios abertos, mentes abertas. Revista de Empreendedorismo e Gestão de Pequenas Empresas, v.5, n.2, 2016 
SANTORO, G.; FERRARIS, A.; GIACOSA, E.; GIOVANDO, G. How SMEs Engage in Open Innovation: a Survey. Journal of the Knowledge Economy, p. 1-14, 2016.

SCHEIN, E. H. Coming to a new awareness of organizational culture. Sloan Management Review, v. 25, n. 2, p. 3-16, 1984.

SCHEIN, E. H. Organizational culture and leadership. 2. ed. San Francisco: Jossey-Bass, 1997.

SILVA, G.; DACORSO, A. L. R. Inovação aberta como uma vantagem competitiva para a micro e pequena empresa. Revista de Administração e Inovação, v. 10, n. 3, p. 251-268, 2013a.

SILVA, G.; DACORSO, A. L. R. Perspectivas de inovação na micro e pequena empresa. Revista Economia \& Gestão, v. 13, n. 33, p. 90-107, 2013 b.

SILVA, G.; DACORSO, A. L. R. Riscos e incertezas na decisão de inovar das micro e pequenas empresas. Revista de Administração Mackenzie, v. 15, n. 4, p. 229255, 2014a.

SILVA, G.; DACORSO, A. L. R. Processo de inovação na micro e pequena empresa: implicações e achados em empresas sergipanas. Revista Pensamento Contemporâneo em Administração, v. 8, n. 3, p. 55-70, 2014b.

SISODIYA, S. R.; JOHNSON, J. L.; GRÉGOIRE, Y. Inbound open innovation for enhanced performance: enablers and opportunities. Industrial Marketing Management, v. 42, n. 5, p. 836-849, 2013.

VENTURINI, K.; VERBANO, C.; BRON, A. Openness and innovation: an empirical analysis in firms located in the Republic of San Marino. International Journal of Engineering, v. 5, n. 4, p. 60-70, 2013.

WEICK, K. The Social Psychology of Organizing. 2. ed. Massachusetts: AddisonWesley, 1979.

WEICK, K. An Introduction to Organizing. In: CORMAN, S. R., et al. Foundations of organizational communication: a reader. New York: Longman, 1990.

WEICK, K. E. A Psicologia Social da Organização. São Paulo: Edgar Blucher: EDUSP, 1973.

WEICK, K. Making sense of the organization: the impermanent organization. UK: John Wiley \& Sons Ltd, 2009.

'Este artigo foi elaborado a partir do apoio da Capes

SILVA, G.; DACORSO, A. L. R.; MONTENEGRO, L. M. Mais do que negócios abertos, mentes abertas. Revista de Empreendedorismo e Gestão de Pequenas Empresas, v.5, n.2, 2016. 